\title{
An Advanced Fault Locating Technique with WAMS based Backup Protection Scheme for Power System with Simultaneous Faults
}

\author{
S. Roy and Dr. P.S. Babu
}

\begin{abstract}
Protection of power systems is important for stable and uninterrupted operation of power network. Maloperation of traditional back up protection schemes (e.g-Zone3 maloperation) causes many catastrophic phenomenon like cascaded tripping in power systems. So, some defensive mechanism are needed for taking care of such failures in power systems and to increase their security and reliability. Due to hugeness and complexity of Modern power systems, they are controlled, monitored and protected by Wide Area Measurement systems (WAMS). WAMS increases the efficiency and reliability of power networks and prevent the chance of blackouts and cascading failures in tandem. A synchronized phasor measurement-based wide-area backup protection scheme is presented in the paper where the magnitude of sequence voltages of buses at a system protection centre are used to identify the faulted area, bus closest to the fault and faulted line. The proposed method is tested for several faults including simultaneous faults in power systems with interconnections also. This technique is found to be Reliable, accurate and fast with contemporary synchronized measurement based technology. It is expected that numerous disastrous blackouts, cascaded tripping of power networks can be avoided and reliability and security of the power systems can be improved by the scheme. The study of new and improved back up protection scheme is done on a WSCC-3 machine-9 bus system. The data is simulated through EMTDC/PSCAD and MATLAB /SIMULINK software.
\end{abstract}

Index Terms-Distance Protection, Simultaneous Faults, Series Compensation, Faulted bus Identification, Backup protection, faulted Line identification, Sequence Components of Voltage, Balanced Fault, Unbalanced Fault.

Symbols

$\boldsymbol{\emptyset}_{1 s}, \boldsymbol{\emptyset}_{1 \mathrm{~s}}{ }^{1}$ - Phase angle between positive sequence Voltage and before and after placement of series capacitor.

$\boldsymbol{\emptyset}_{2 s}, \boldsymbol{\emptyset}_{2 s}{ }^{1}$ - Phase angle between negative sequence Voltage and current before and after placement of series capacitor.

Ø1R - Phase angle between positive Sequence Voltage and current at the other end of the protected line.

$\boldsymbol{\emptyset}_{2 \mathrm{R}}$ - $\quad$ Phase angle between negative Sequence Voltage and current at the other end of the protected line.

$\boldsymbol{\emptyset}_{2 \mathbf{R}}$ - Phase angle between negative Sequence Voltage and current at the other end of the protected line.

S. ROY, Research Scholar, Department of Electrical Engineering, NIT Warangal, India, (email: saptarshi.roy.ju@gmail.com).

Dr.P.S. BABU, Assistant Professor, Department of Electrical Engineering, NIT Warangal, India, (email: drsureshperli@ nitw.ac.in).

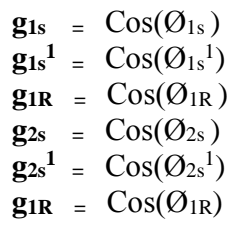

\section{INTRODUCTION}

TN GENERAL local voltage or current measurements are used in conventional back up protection schemes used for power networks which find obstacle in distinguishing the fault from heavy loading conditions [1]. Maloperation of back up protection during stressed conditions causes the cascaded tripping. Wide area interconnection leads to huge number of blackouts throughout the world.

Recent advancements in technology draws significant attention for the utilization of the synchronized phasor measurement unit (PMU) based wide-area measurement system (WAMS) for power system protection [2,3]. Emergence of new technologies like smart electric grid increased the safety and reliability power networks and mitigates the more serious consequences like blackouts, cascaded tripping of power networks and other power outages. Thus they help to continue safe, reliable and continuous power supply.

The largest power outage in history happened in India on 30 th and $31^{\text {st }}$ July 2012. The outage affected 22 states in Northern, Eastern and Northeast India. About 32000MW of generating capacity was taken offline in the outage. Several factors responsible for the blackout were:

i) Weak inter-regional power transmission due to multiple existing outages.

ii) Drastically increase in loading on $400 \mathrm{kV}$ BinnaGwalior-Agra power link.

iii) Inadequate response by State Load Dispatch Centres (SLDCs). This outage affects most of the population of India (about 620 million).

iv) Loss of $400 \mathrm{kV}$ Binna-Gwalior link due to maloperation of the protection system [12].

The wide-area backup protection (WABP) based on faulted line identification (FLI) is an interesting topic of research in recent days due to several reasons. First of all a good backup protection can increase the security and reliability of power system. Second of all, a good back up protection can ensure a stable and uninterrupted flow of power. Thus, it reduces power 
outage and loss of production in plants. The proposed technique can overcome the limitations of conventional backup protection and allows faster operation since it does not need coordination among different zones.

Different WABP schemes for FLI are discussed [4-8]. In [4], a WABP is proposed that compares the positive-sequence voltage magnitude at each bus during the fault to identify the closest bus to the fault. Positive-sequence current angles of all lines connecting the selected bus are used to detect the line having fault. In [5] the residual vector of a Synchro-phasor based state estimator, used in a supervisory system, is proposed to improve security of an existing remote backup protection scheme. A supervisory and an agent-based ad-hoc backup relay protection scheme based on a network infrastructure and communication are proposed in [6].

A WABP scheme based on the fault steady-state component of voltages and currents is proposed for Faulted line identification in [7]. In that method, subsets of buses, called protection correlation regions (PCRs), are formed on the basis of network topology and PMU placement. The steady-state component of differential currents in each region is used to identify the PCR with the fault. A WABP algorithm based on the fault component voltage distribution is proposed in [8]. In this scheme, the faulted voltage at one terminal of the line is estimated by the measured values of faulted voltage and current at other terminals, and the faulted line is identified based on the ratio of estimated values to measured values. A faulted area detection technique is also used to accelerate the faulted line identification task. In $[12,13]$, synchronized phasor measurement based back up protections are suggested but those schemes deal with only one fault at a time occurred in a power network. But faults or contingencies in a power network is not an isolated issue. In fact, more than one fault or contingencies can occur in a power network, especially in a Wide area network, at a time or simultaneously. But nothing is discussed about power systems behaviour if more than one fault or contgencies occurred in power network simultaneously, in any of the above methods. In this paper, the method discussed is an advanced version of the method discussed in $[12,13]$, which is modified and extended up to describing the behaviour of power systems during simultaneous faults.

A series capacitor with Metal Oxide Varistor creates problems to distance relaying based transmission-line protection. Typical problems associated with relays have been addressed in [9-10] which include several critical phenomena like voltage/current inversion, sub harmonic oscillations, and additional transients caused by the air-gap operation [19]. Performances of available WABP schemes [4-8] have not been evaluated for series-compensated lines and may find limitation for such lines. This paper proposes a WABP scheme where angle information between voltage and current at both ends of a line is used for faulted line identification. The scheme is found to be accurate for the compensated and uncompensated line from the evaluation for a $400-\mathrm{kV}$, 9-bus system with simultaneous faults also. In this paper several cases have been studied to justify the proposed technique.

\section{WIDE AREA SYNCHROPHASOR SYSTEM WITH PHASORS OF NOMINAL FREQUENCY SIGNALS}

Nominal frequency means desired central frequency. In case of a signal, the desired central frequency is the same as source or generation frequency. If it deviates from desired central frequency, then it is called off-nominal.

Let us consider a constant input signal $x(t)$, with nominal frequency $\mathrm{f}_{0}$ [5].It is sampled at a sampling frequency $\mathrm{Nf}_{0}$. The sampling angle $\varnothing=2 \pi / \mathrm{N}$, and the phasor estimation is done below :

$X(t)=X_{m} \operatorname{Cos}\left(2 \pi f_{0} t+\varnothing\right)$

The data samples of this input $X_{n}:\{n=0,1,2, \ldots, N-1)$ are $\mathrm{X}_{\mathrm{n}}=\mathrm{X}_{\mathrm{m}} \operatorname{Cos}(\mathrm{n} \varnothing+\bar{\delta})$

$$
\begin{aligned}
\mathrm{X}_{\mathrm{c}}^{\mathrm{n}-1} & =\sqrt{2} / N \sum_{n=0}^{N-1} X_{\mathrm{n}} \operatorname{Cos}(\mathrm{n} \varnothing+\delta) \\
& =\sqrt{2} / N \sum_{n=0}^{N-1} X_{\mathrm{m}} \operatorname{Cos}(\mathrm{n} \varnothing+\delta) \cdot \operatorname{Cos}(\mathrm{n} \varnothing) \\
& =(\sqrt{2} / N) \mathrm{X}_{\mathrm{m}} \sum_{n=0}^{N-1}\left[\operatorname{Cos} \delta \operatorname{Cos}^{2} \mathrm{n} \varnothing-\frac{1}{2} \operatorname{Sin} \delta \cdot \operatorname{Sin}(2 \mathrm{n} \varnothing)\right] \\
& =\mathrm{X}_{\mathrm{m}} / \sqrt{2} \operatorname{Cos} \delta
\end{aligned}
$$

Similarly

$$
\begin{aligned}
\mathrm{X}_{\mathrm{s}}^{\mathrm{N}-1} & =\sqrt{2} / N \sum_{n=0}^{N-1} X_{\mathrm{n}} \operatorname{Sin}(\mathrm{n} \delta) \\
& =-\mathrm{X}_{\mathrm{m}} / \sqrt{2} \operatorname{Sin} \delta
\end{aligned}
$$

The Phasor $\begin{aligned} \mathrm{X}^{\mathrm{N}-1} & =\mathrm{X}_{\mathrm{c}}^{\mathrm{n}-1}-\mathrm{j} \mathrm{X}_{\mathrm{s}}^{\mathrm{n}-1} \\ & =\mathrm{X}_{\mathrm{m}} / \sqrt{2}[\operatorname{Cos} \delta+j \operatorname{Sin} \delta] \\ & =\mathrm{X}_{\mathrm{m}} / \sqrt{2} e^{j \delta}\end{aligned}$

A synchro-phasor based system having several components .e.g- Phasor measurement unit (PMU), phasor data concentrator (PDC), GPS satellite system, super PDC (SPDC) as shown in Fig.1(a) \& Fig.1(b). The real time data from the various remote areas are collected by PMUs and sent to local data concentrator called phasor data concentrator through communication system. This system is same as the backup protection system for Wide Area Protection System (WAPS) and it is capable of acting as the substitution of conventional backup protection in power system [12]. The relay decision is taken based on collected data via communication network. The suggested technique increases the accuracy, reliability and stability of the system.

Usually the data collection activity follows the below hierarchy. Level 1 being the lowest and level 4 is the highest position as indicated in Fig.1(a). In case of a power network level 1 can be compared as feeder level data, level 2 can be compared as substation level data, level 3 can be compared with a State board or grid data and level 4 can be compared with a load dispatch centre data (e.g - Northern Regional Load dispatch centre or Southern Region Load dispatch centre in context to India). 


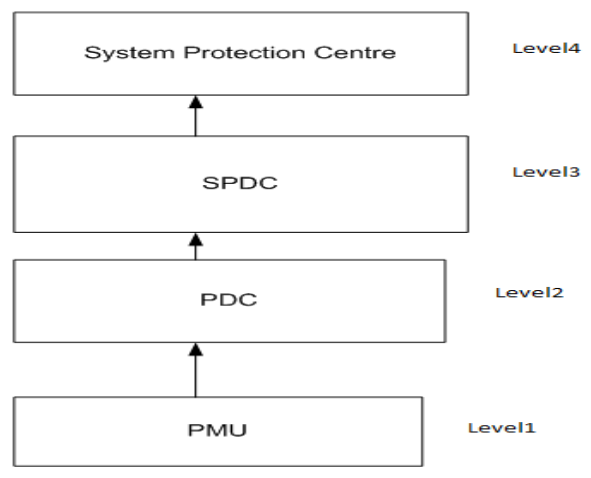

Fig.1(a). Collection of Data Hierarchy

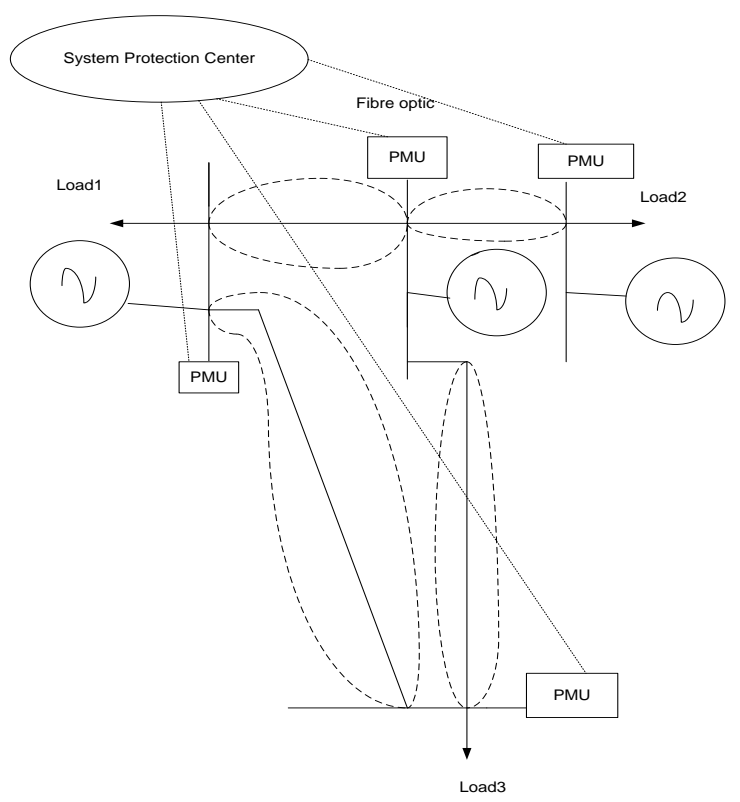

Fig.1(b). Wide Area Measurement Back Up Protection

\section{PROPOSED METHOD}

The main purpose of this proposed technique is to improve wide area monitoring and system event analysis. The proposed technique is useful for monitoring and control of large power networks like plants, transmission lines and significant control points of the grid [13]. Synchro-phasor using phasor measurement unit provides all significant measurements required for the operation including voltage magnitudes, phase angles and frequency. The rate of data sampling is maintained at $4 \mathrm{kHz}$. Channel plot step in project settings of EMTDC/PSCAD is kept at 250 micro-seconds.

The Proposed Technique is follows:

\section{Algorithm:}

Step1: Start

Step2: Collect all data from all PMUs and PDCs in real time.

Step 3: Obtain minimum positive sequence voltage magnitude or maximum negative or zero sequence magnitude $\left(\mathrm{v}_{\mathrm{k}}\right)$

Step4: Compare with the threshold value. If it is less than minimum positive sequence voltage magnitude or more than maximum negative or zero sequence magnitude value, then there is no fault in the system. Otherwise, area or bus $k$ is the nearest to the fault go to Step5 and Proceed

Step5 : Check whether it is a balanced fault or unbalanced fault.

The negative- and zero-sequence voltages are used to identify unbalanced faults [13]. For these faults, the pickup criterion is defined as,

$$
\mathrm{V}_{\mathrm{m} 2} \geq \mathrm{K}_{2} \mathrm{~V}_{\mathrm{n}} U \mathrm{~V}_{\mathrm{m} 0} \geq \mathrm{K}_{0} \mathrm{~V}_{\mathrm{n}}
$$

Where $\mathrm{V}_{\mathrm{m} 2}$ \& $\mathrm{V}_{\mathrm{m} 0}$ are the negative and Zero sequence components of the waveform of $\mathrm{m}^{\text {th }}$ bus and $\mathrm{V}_{\mathrm{n}}$ is the rated voltage of the bus. $K_{2}$ and $K_{0}$ are the constants. In this paper, the thresholds of $\mathrm{K}_{2}$ and $\mathrm{K}_{0}$ and set at 0.1 for an unbalanced fault. The reason of choosing low threshold settings are that the combined information of negative and zero-sequence voltage magnitudes could improve the sensitivity of pickup criterion during a high-resistance earth fault.

If unbalanced fault condition is not satisfied, then the substation will check for balanced fault criterion:

$$
\mathrm{V}_{\mathrm{m} 1} \leq \mathrm{K}_{1} \mathrm{~V}_{\mathrm{n}}
$$

$\mathrm{K}_{1}$ is a constant whose value is kept 0.6 in this paper. Higher threshold for the balanced fault is chosen in order to avoid frequent pickup of the WABP system under normal switching condition of the power Network.

Step6: Compute absolute angle difference of all lines connected to bus or area $\mathrm{k}$.

Step7: Obtain highest value line of phase angle.

Step8: The $\mathrm{j}^{\text {th }}$ line connected to area $\mathrm{k}$ is faulted line.

Step9: Authentication if series capacitor compensation involved in the faulted line: Check $\mathrm{g}_{2 \mathrm{~s}}, \mathrm{~g}_{2 \mathrm{~s}}{ }^{\prime}, \mathrm{g}_{2 \mathrm{R}}$ all $>0$ (6) for an unbalanced fault.

Check,

$$
\mathrm{g}_{1 \mathrm{~s}}, \mathrm{~g}_{1 \mathrm{~s}}, \quad \mathrm{~g}_{1 \mathrm{R}} \text { all }>0
$$

for a balanced fault.

Step10 : Relaying algorithm

Step11 : Stop

\section{CASE STUDIES}

The proposed Wide Area Measurement Back up protection (WABP) algorithm is tested for a WSCC 3-Machine-9 bus system (same as Fig 2). Using EMTDC/PSCAD and MATLAB/SIMULINK software simulations are carried out for different types of fault and even simultaneous faults in different branches of the system (both balanced and unbalanced faults). The data sampling rate is maintained at 4 $\mathrm{KHz}$ throughout. Solution time step is kept at 50 microsecond and channel plot step is kept 250 micro seconds in project settings of EMTDC / PSCAD for capturing data (in case used EMTDC/PSCAD for WSCC-3-Machine-9 bus system 
simulation). In figure 6, Simulink implementation of WSCC3-Machine-9 bus system is shown.

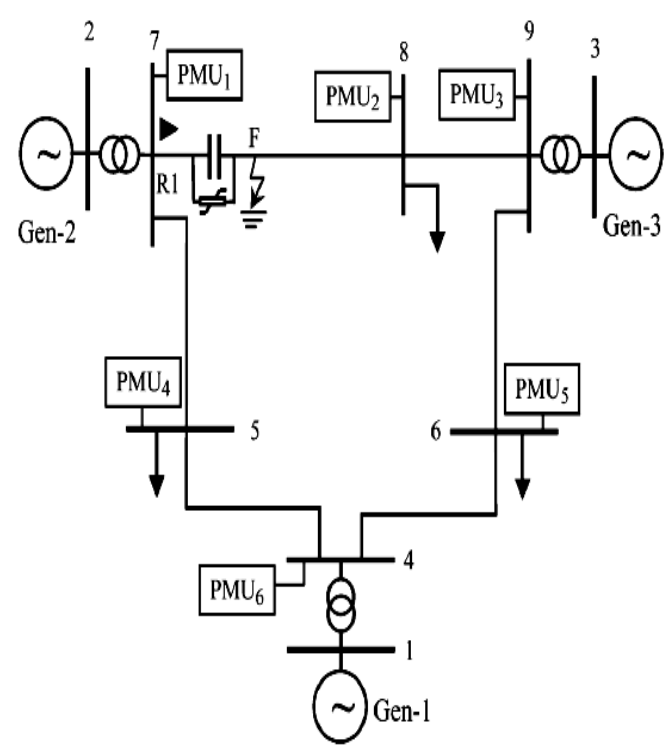

Fig.2. Single Line Diagram of WSCC-3Machine-9bus system with PMUs.

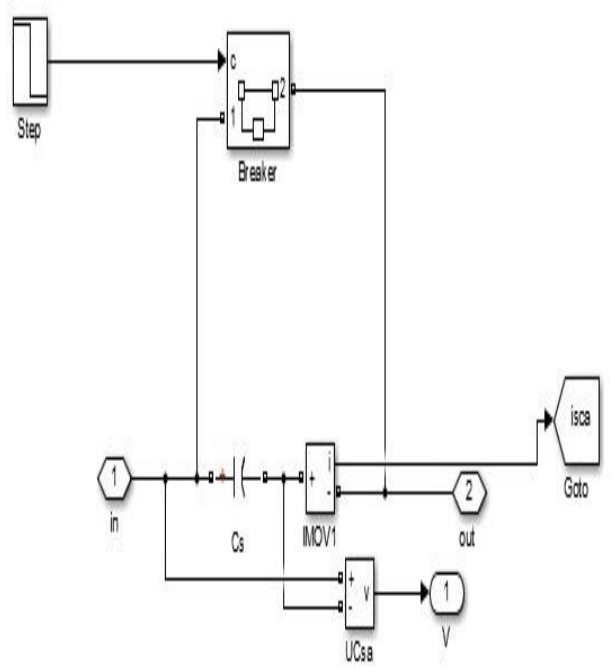

Fig.3. Simulink Design of MOV Circuit with different protections.
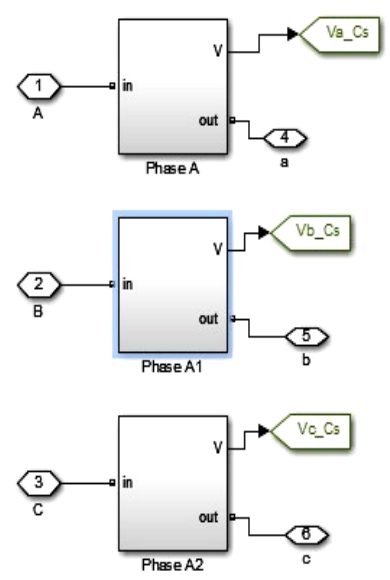

Fig.4. Simulink Design of Data Acquisition system
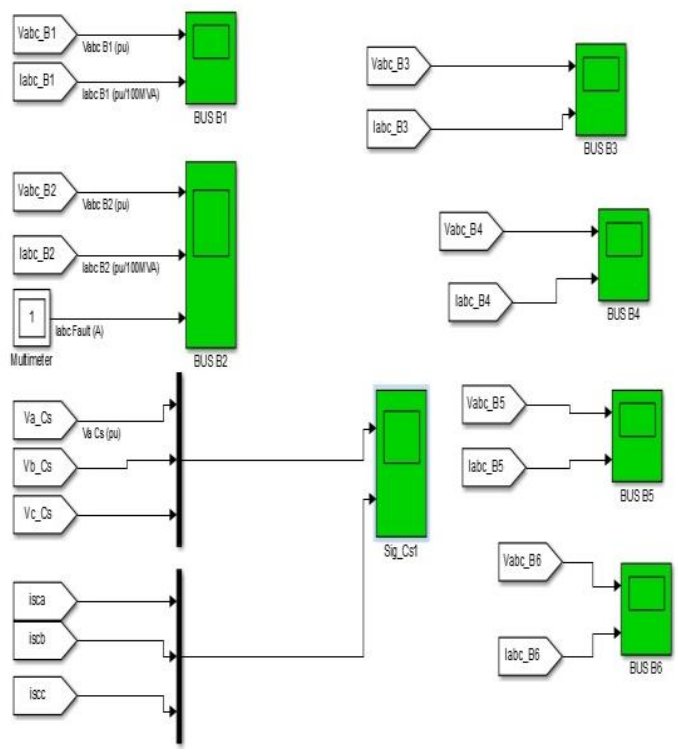

Fig. 5. Design of Data Acquisition with Simulink.

Fig.6 is showing Simulink implementation of WSCC-3Machine-9 bus system. Fig.3, Fig.4 and Fig.5 are showing different internal protections and arrangement of data acquisition by Simulink software required for the work. 


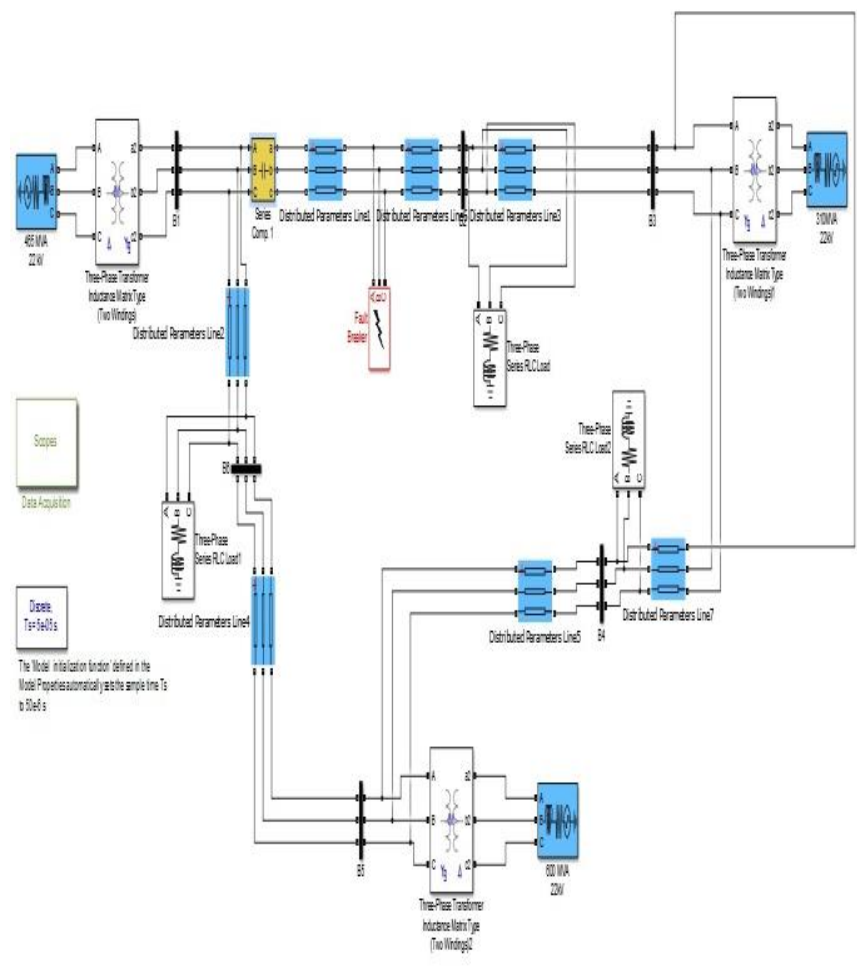

Fig.6. Simulink Implementation of 9 bus system

\section{A. Case-i : LG fault :}

An LG fault (AG-type) is created at $0.34 \mathrm{sec}$. on line 5-7 at a distance of $30 \mathrm{~km}$ from bus- 5 for $0.04 \mathrm{sec}$. A capacitor is used in Line 5-7 with $40 \%$ compensation. The waveform got from different buses are studied below:

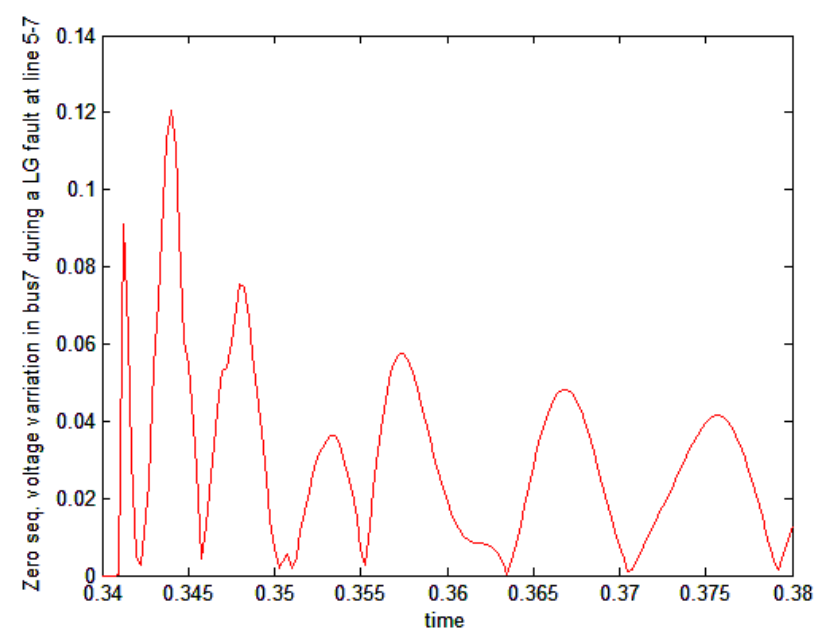

Fig.7(a). Zero Sequence Voltage Profile at bus7.

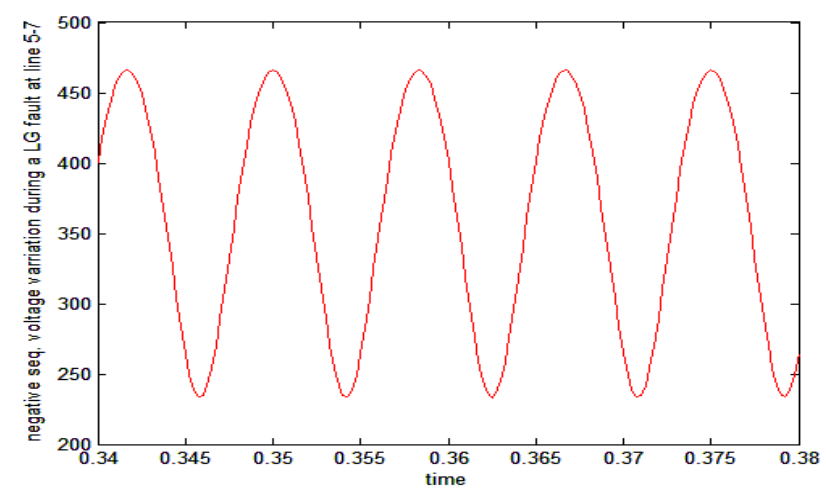

Fig7(b):Negative Sequence Voltage Profile at bus5.

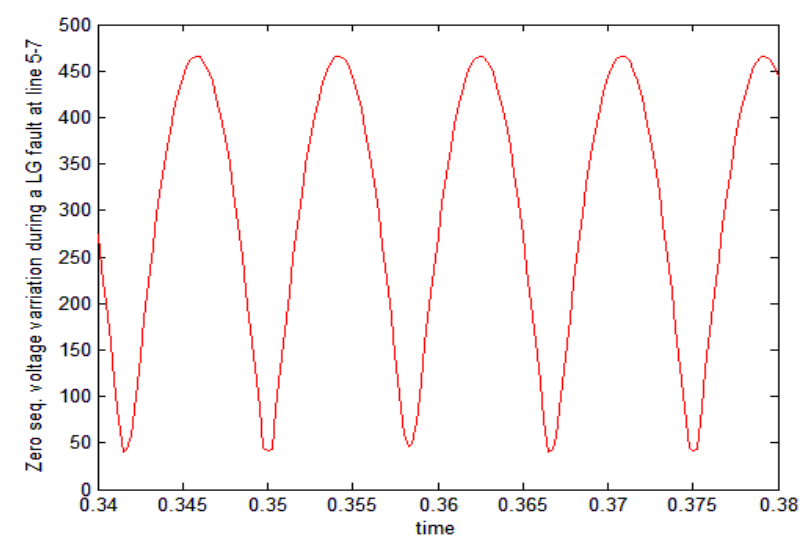

Fig.7(c). Zero Sequence Voltage Profile at bus5.

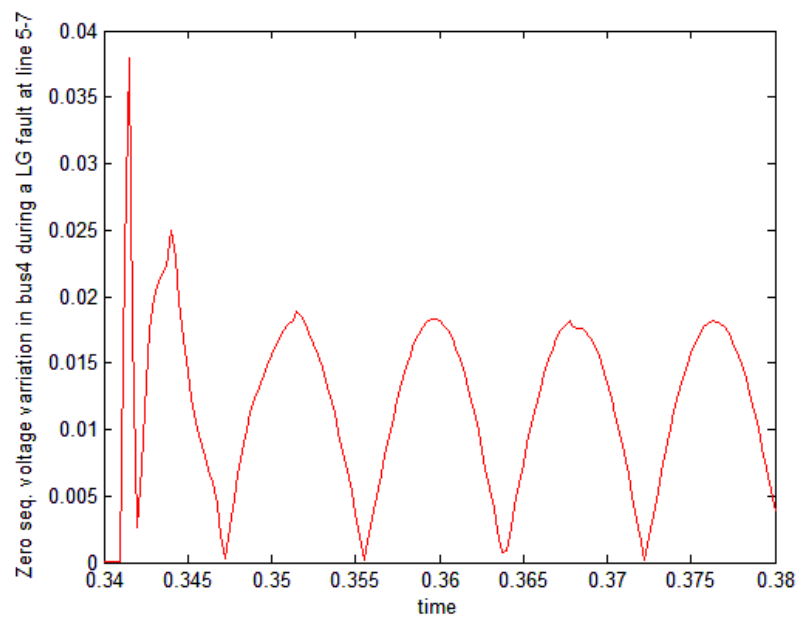

Fig.7(d). Zero Sequence Voltage Profile at bus4. 


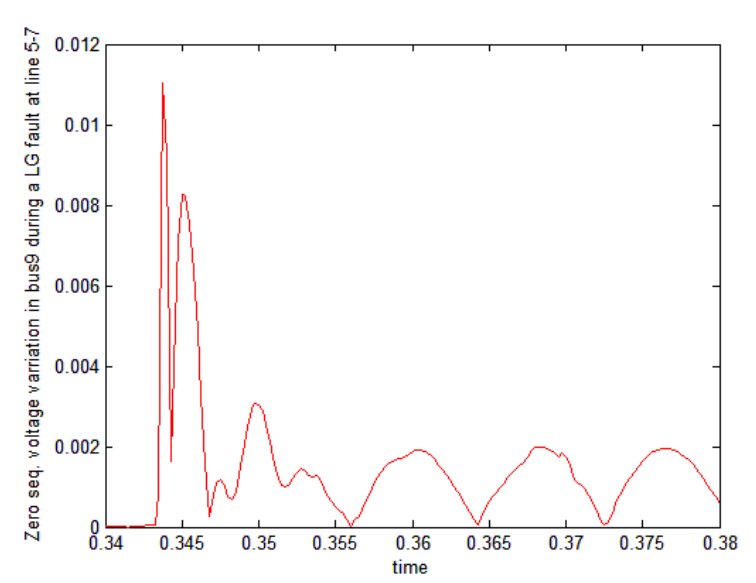

Fig.7(e). Zero Sequence Voltage Profile at bus9

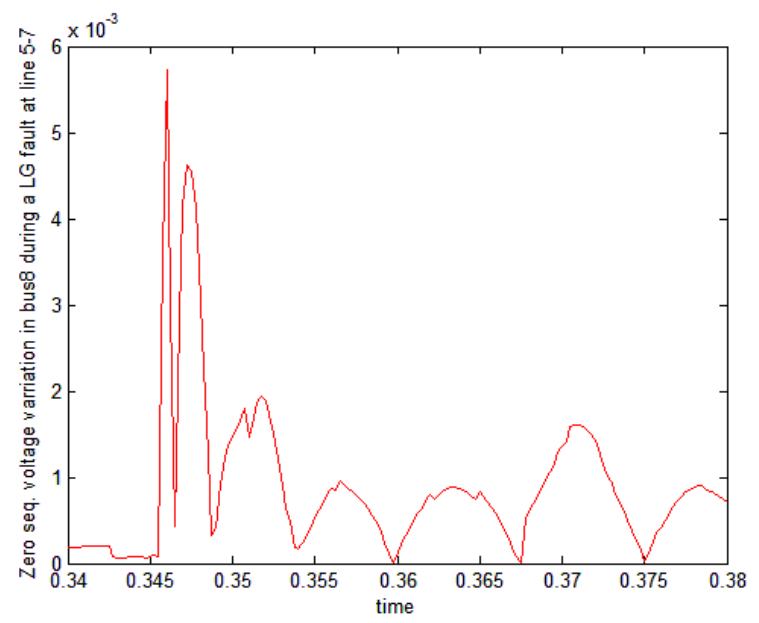

Fig.7(f). Zero Sequence Voltage Profile at bus8

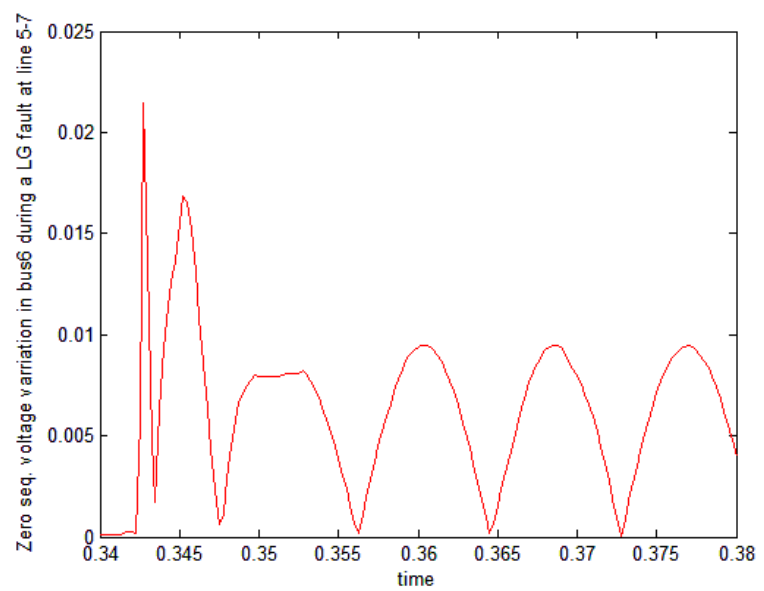

Fig.7(g). Zero Sequence Voltage Profile at bus6

The observation of the figures 7(a), 7(b), 7(c), 7(d), 7(e), 7(f), $7(\mathrm{~g})$ clearly shows it satisfies the equation (4), the pickup condition for unbalanced fault as:

$$
\mathrm{K}_{2} \mathrm{~V}_{\mathrm{n}}=40 \mathrm{KV} \quad \mathrm{K}_{0} \mathrm{~V}_{\mathrm{n}}=40 \mathrm{KV}
$$

Bus 5 zero sequence voltage profile having maximum voltage magnitude among other buses in the network. So, the bus 5 data satisfy the criterion for an unbalanced fault and as bus 5 having maximum zero sequence magnitude, Bus5 is closest to the fault.

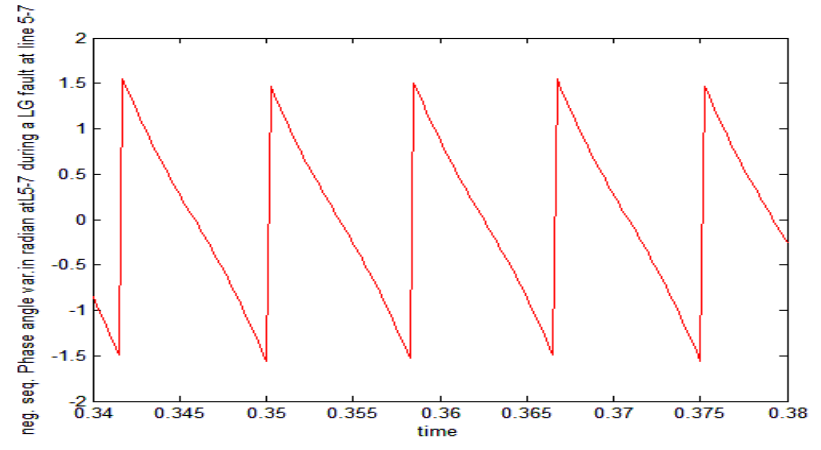

Fig.8(a). Phase Variation Line 5-7

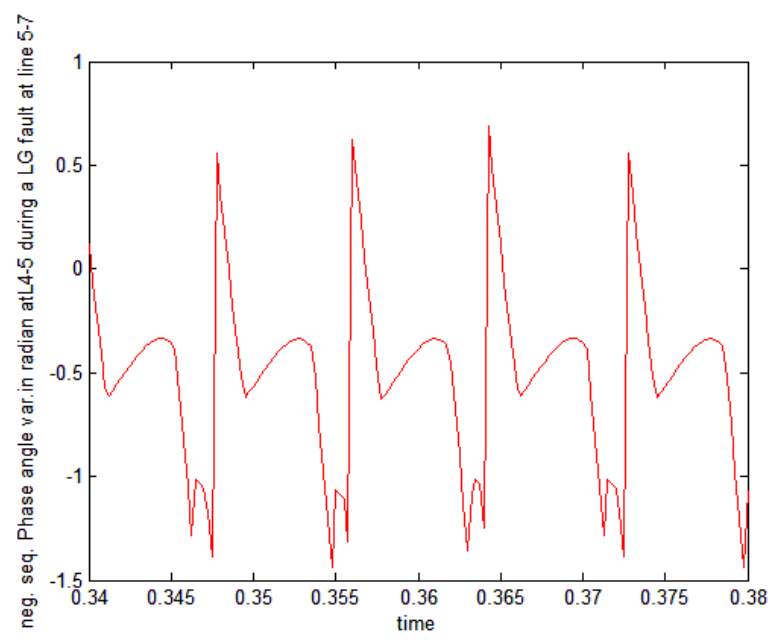

Fig.8(b). Phase Variation Line 4-5

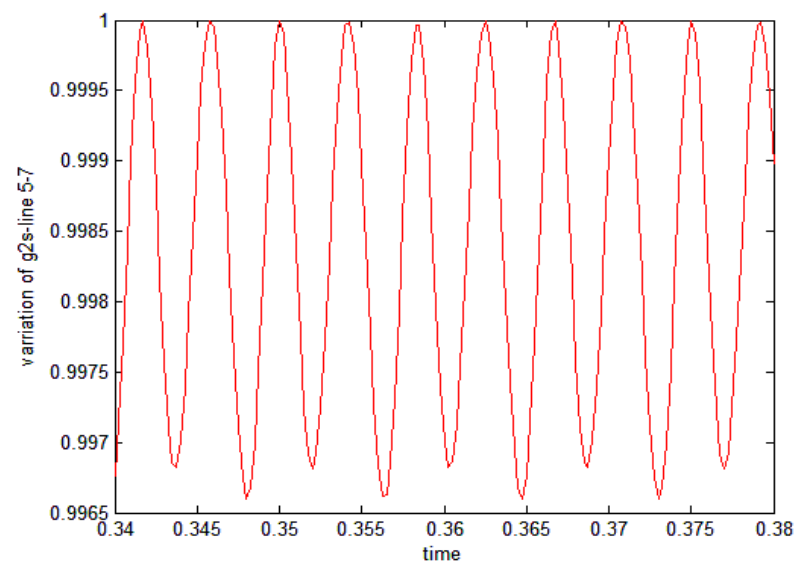

Fig.9(a). $g_{2 s}$ profile during LG fault

Two lines are adjacent to bus5.Line 5-7 and Line 4-5. The negative sequence phase variation is shown for those two lines are in figure 8(a), 8(b).The phase variation is expressed in radian. It is seen the variation of phase lies between $-\pi / 2$ to $+\pi / 2$ or -90 degree to +90 degree. 


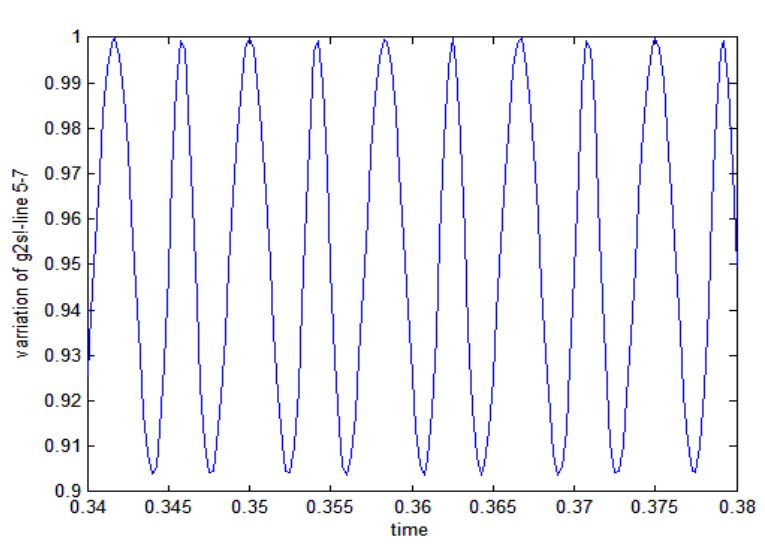

Fig.9(b). $\mathrm{g}_{2 \mathrm{~s}}{ }^{1}$ profile during LG fault.

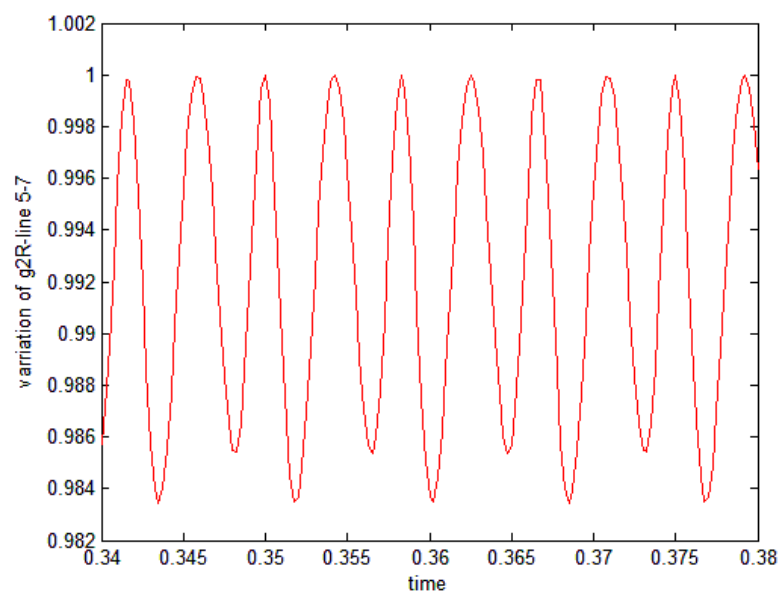

Fig.9(c). $g_{2 R}$ 'profile during LG fault

From the figures 8(a), 8(b) and 9(a), Fig.9(b), Fig.9(c), it is clear that line 5-7 is satisfying the equation (6), hence the criterion and authentication of an unbalanced fault .

So, line 5-7 is the faulted line.

\section{B. Case-ii : LLL fault:}

a 3-phase fault is created at $0.34 \mathrm{~s}$ on line 5-7 at a distance of $30 \mathrm{~km}$ from bus-5 for $0.04 \mathrm{sec}$. After collecting all data, the following analysis has been done:

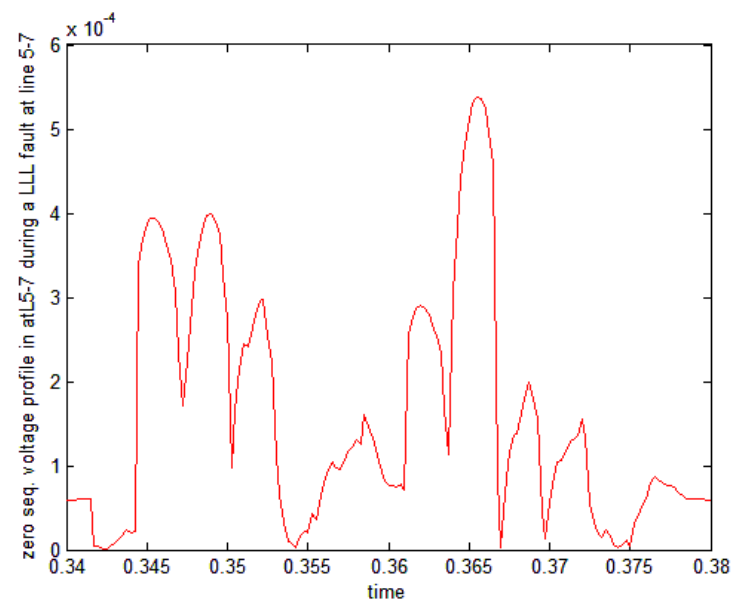

Fig.10(a). Zero Sequence Voltage Profile at bus5.

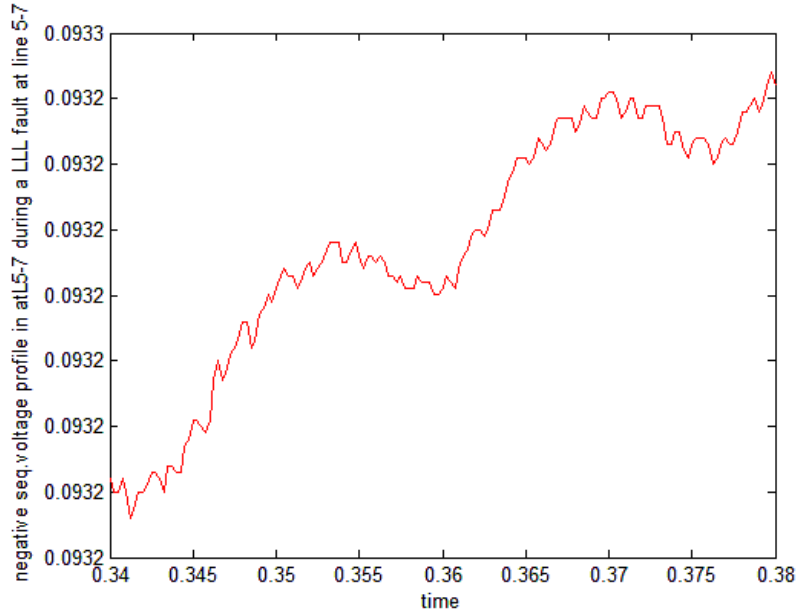

Fig.10(b). Negative Sequence Voltage Profile at bus5.

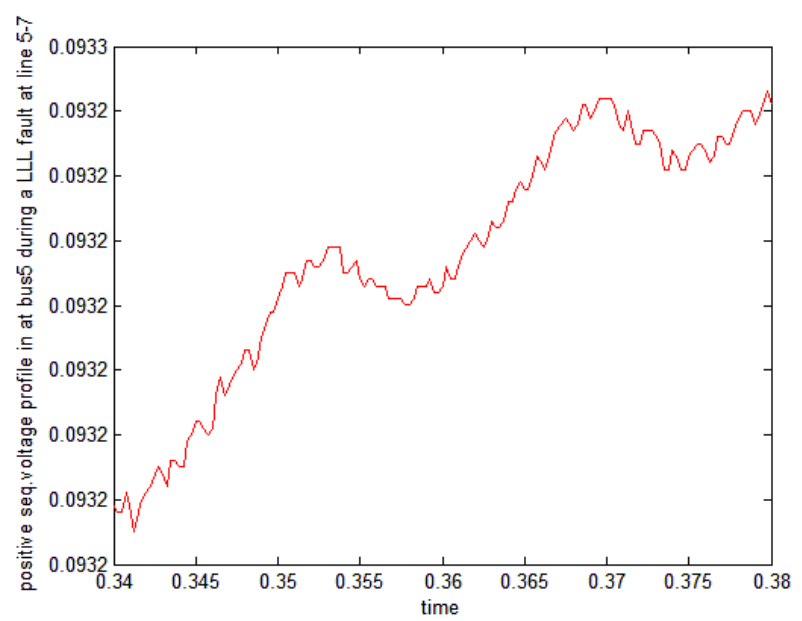

Fig.10(c). Positive Sequence Voltage Profile at bus5.

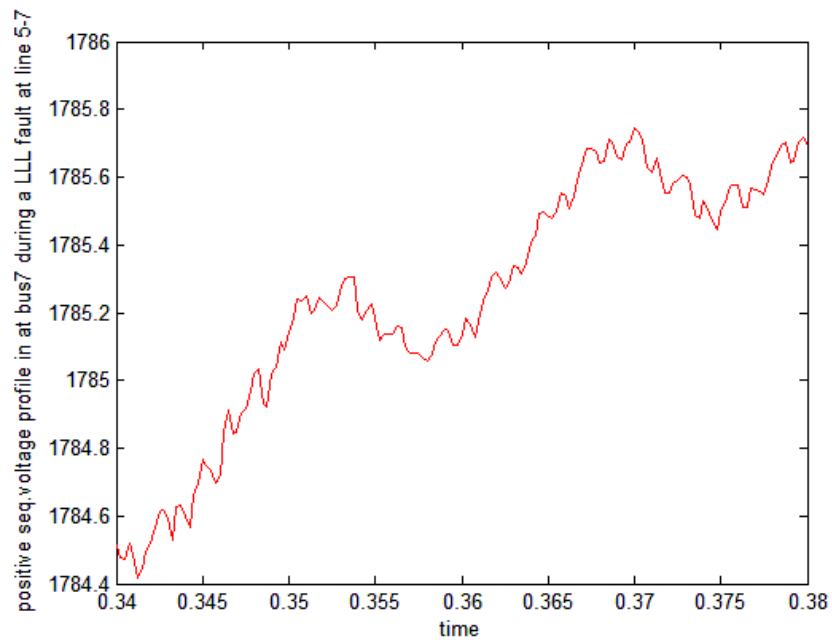

Fig.10(d). Positive Sequence Voltage Profile at bus7. 


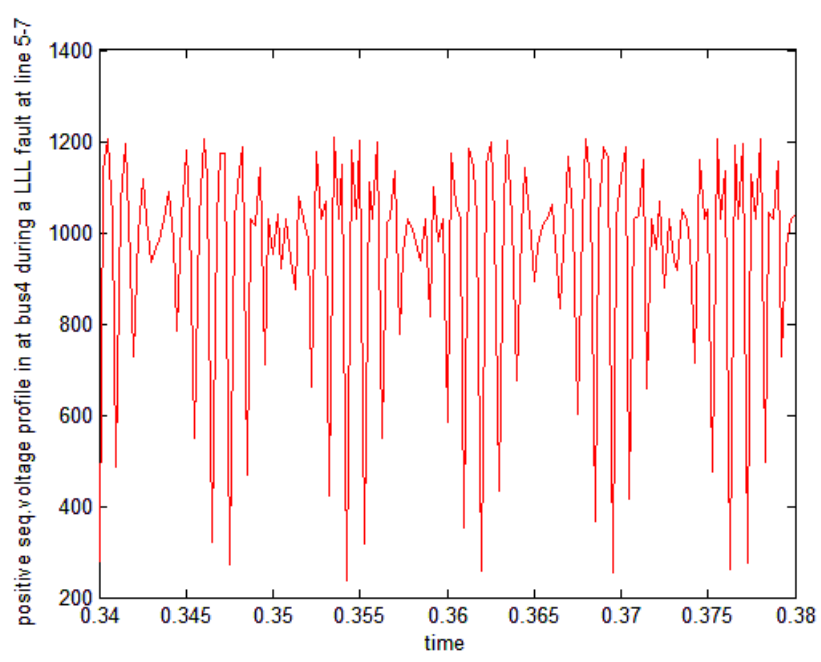

Fig.10(e). Positive Sequence Voltage Profile at bus4.

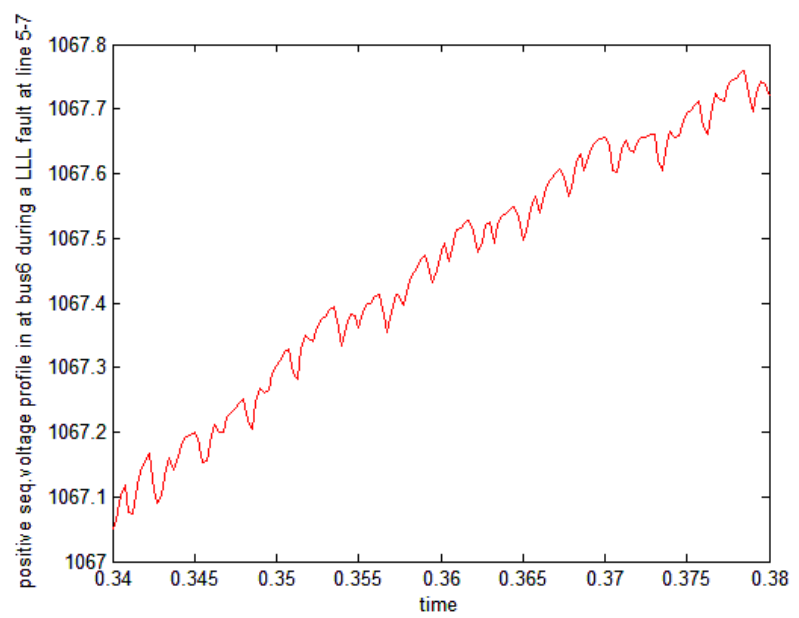

Fig.10(f ). Positive Sequence Voltage Profile at bus6.

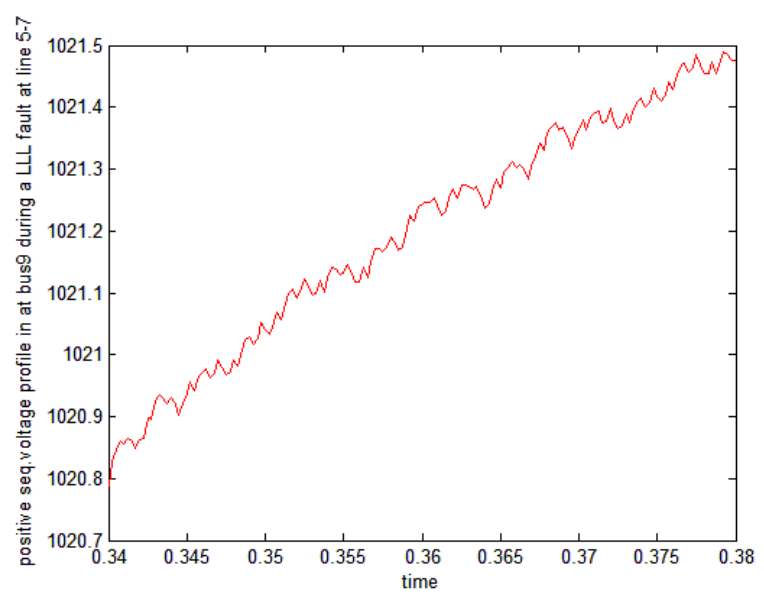

Fig.10(g). Positive Sequence Voltage Profile at bus9.

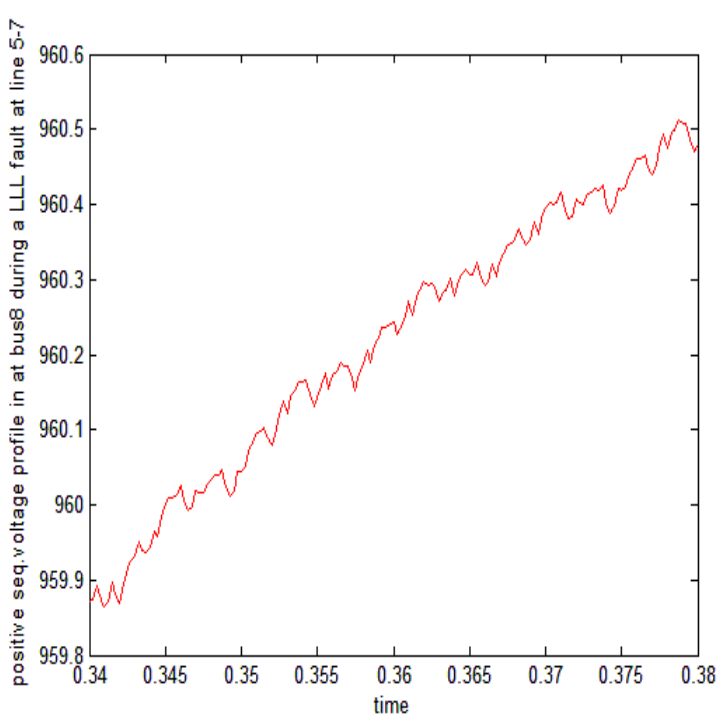

Fig.10(h). Positive Sequence Voltage Profile at bus8.

All the units of voltage are expressed in Kilo Volt (KV) here and time in second. The observation of the figure 10(a), 10(b), $10(\mathrm{c}), 10(\mathrm{~d}), 10(\mathrm{e}), 10(\mathrm{f}), 10(\mathrm{~g}), 10(\mathrm{~h})$ clearly shows it does not satisfy equation (4), the pickup condition for unbalanced fault.

$$
\text { as } \quad \begin{aligned}
\mathrm{V}_{\mathrm{m} 2} & \leq \mathrm{K}_{2} \mathrm{~V}_{\mathrm{n}} \& \& \mathrm{~V}_{\mathrm{m} 0} \leq \mathrm{K}_{0} \mathrm{~V}_{\mathrm{n}} \\
\mathrm{K}_{2} \mathrm{~V}_{\mathrm{n}} & =40 \mathrm{KV} \quad \mathrm{K}_{0} \mathrm{~V}_{\mathrm{n}}=40 \mathrm{KV}
\end{aligned}
$$

But it satisfies equation (5), the pickup criterion of a balanced fault as:

$$
\mathrm{K}_{1} \mathrm{~V}_{\mathrm{n}}=240 \mathrm{KV} \text {. }
$$

and minimum value of positive sequence voltage exist in bus5. So, bus 5 can be considered as bus nearest to the fault.

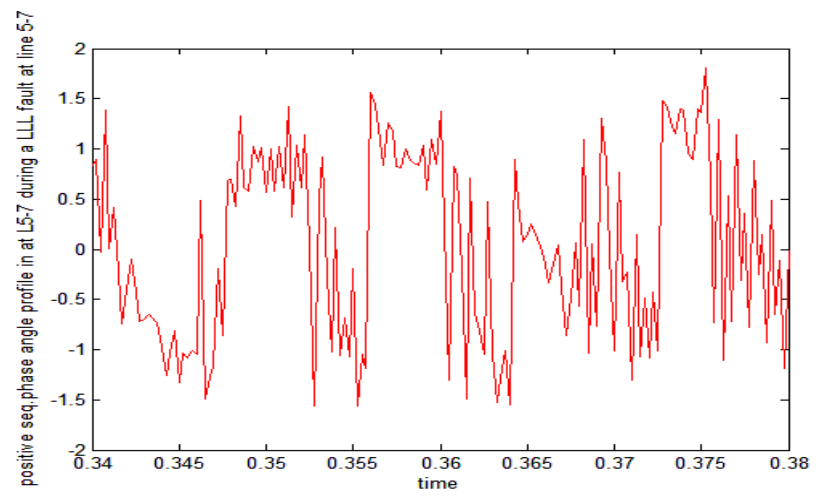

Fig.11(a). Phase Variation Line 5-7.

From the figures11(a), 11(b), 11(c) and 12(a), 12(b), 12(c) it is clear that line 5-7 is satisfying equation (7), and hence the criterion and authentication of a balanced fault. So, line 5-7 can be considered as the faulted line. 


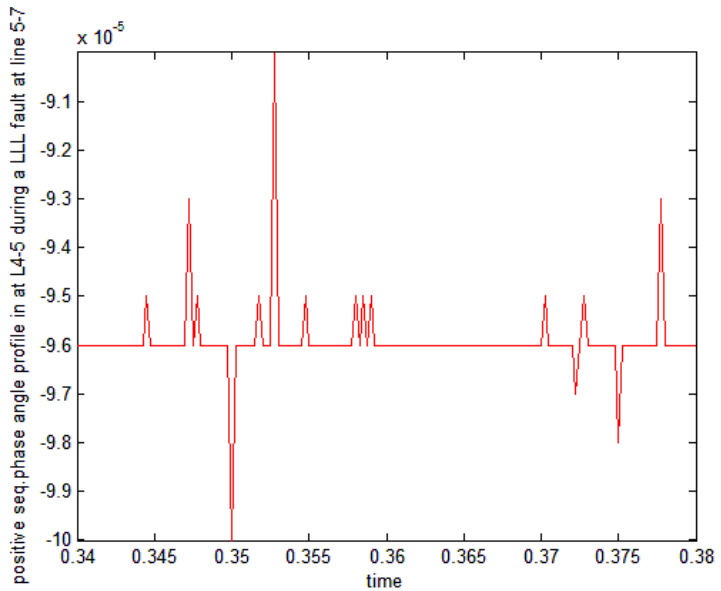

Fig.11(b).Phase Variation Line 4-5.

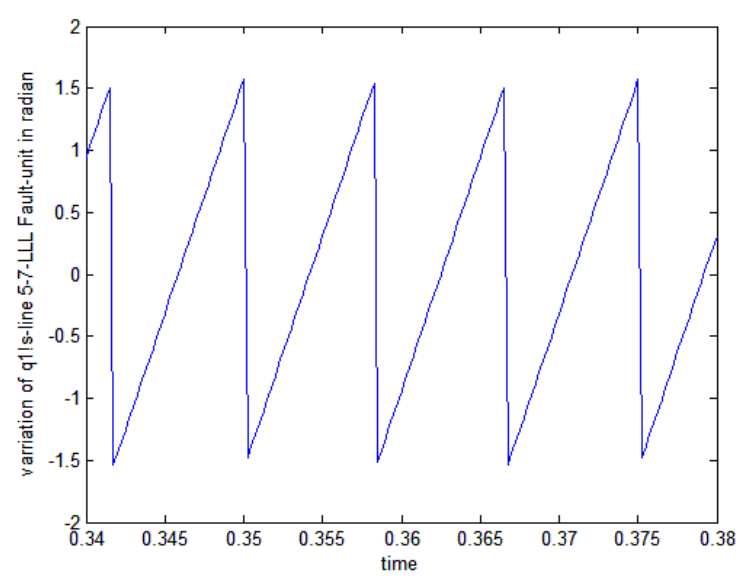

Fig.11(c ).Variation of , $\varnothing_{1 \mathrm{~s}}$ ' for Line 5-7

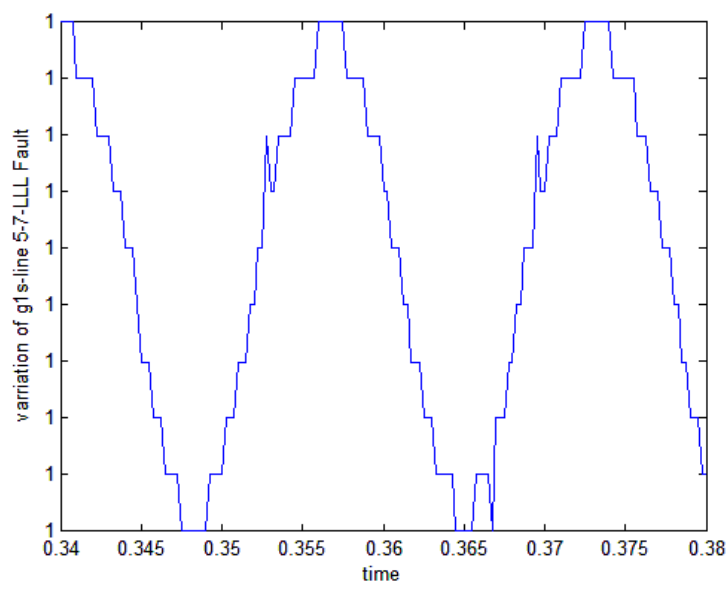

Fig.12(a). g g $_{\text {s }}$ profile during LLL fault.

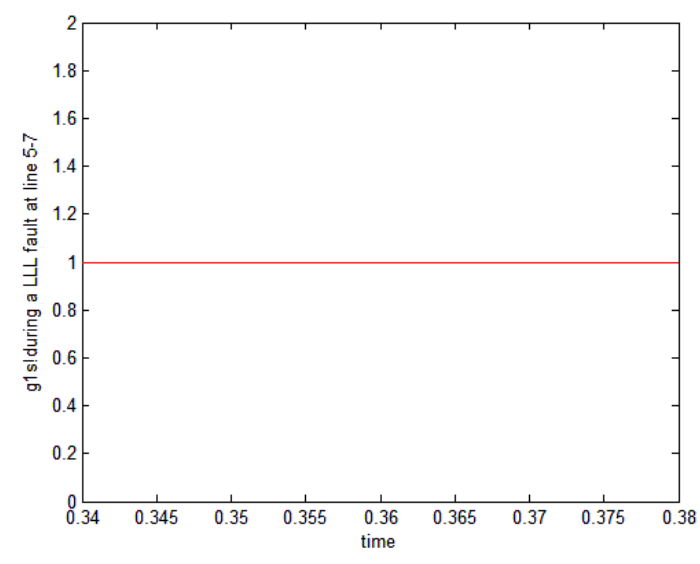

Fig.12(b). $\mathrm{g}_{1 \mathrm{~s}}$ ' profile during LLL fault.

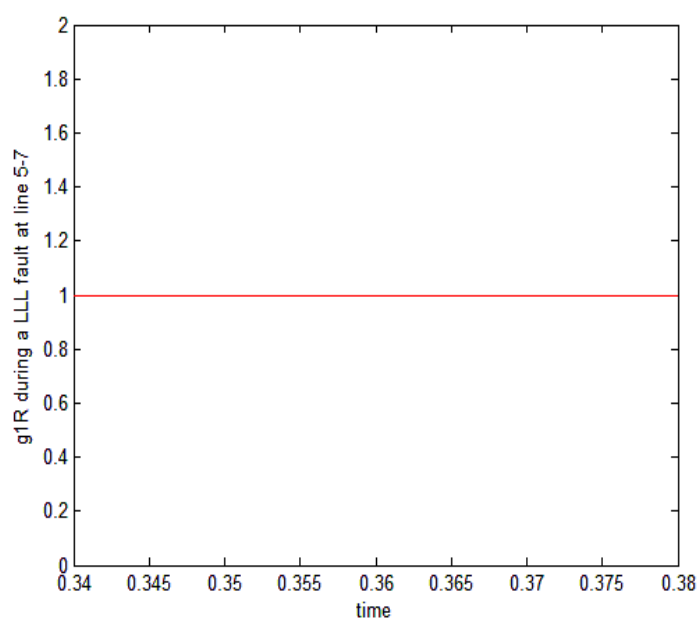

Fig.12(c). $g_{1 R}$ profile during LLL fault

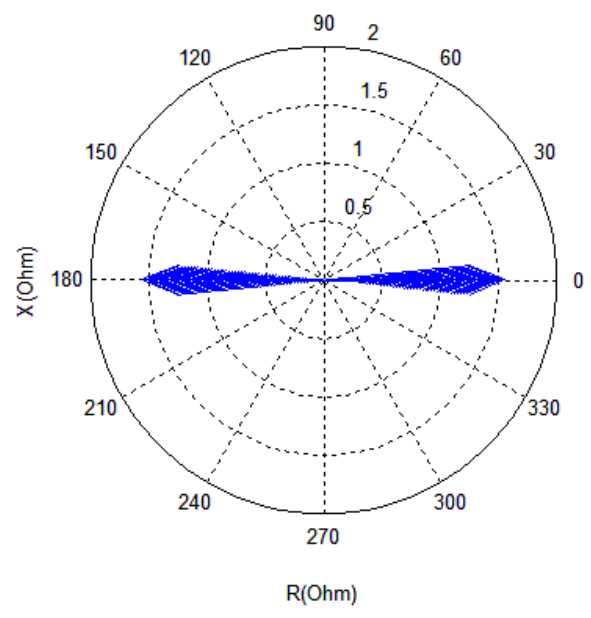

Fig.13(a). Positive Sequence Impedance Trajectory in Z-ø plane. 


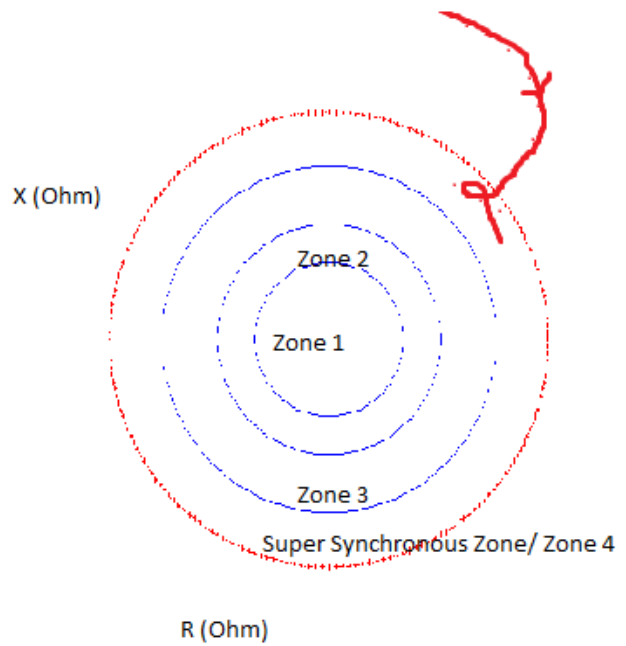

Fig.13(b). Positive Sequence Impedance Trajectory in Z-ø plane enters super synchronous zone (zone 4).

The positive sequence impedance of the test system seen by the relaying point during the fault is plotted in the impedance plane (Fig 13( a)). From the trajectory of the fault impedance, it can be concluded which zone the locus is confined and whether distance relay is going to generate any trip signal to circuit breaker or not and if there is any chance for evolving load encroachment problem or not. Fig.13(b) is showing another case of analysis of system behavior through analysis of impedance trajectory. Here we are considering another circle apart from 3 circles of 3-zone characteristics of relay, encircling zone 3 or relay characteristics. We are calling it as super synchronous zone or zone 4 of the relay. Zone 4 boundary is chosen very nearer to the boundary of zone 3 but greater than zone 3 circle boundary. If from the study of impedance characteristics of a system, we found that impedance trajectory entered in zone 4 or super synchronous zone of the relay characteristics then the system can be distinguished as prone to fault or prone to generate trip signal to the circuit breaker of the system. So, it can be said that, the system need precaution. This analysis can be used in case of condition based monitoring of the system to increase its reliability or security of operation. Thus the impedance trajectory is very helpful in judging several critical conditions of power systems including power swing or dynamic loading conditions (load encroachment etc.), fault prone conditions etc.

\section{Case-iii: Simultaneous Faults:}

Protection of power systems or occurrence of faults in a power network is not an isolated task. It may happen simultaneously. So, now the new WABP algorithm is tested under the condition of occurrence of simultaneous faults across the power network. And here also it is found that it is having immunity to support simultaneous occurrence of faults phenomena.

a) Bus5 and Bus9 both involved with LLL fault:

a LLL fault is created at $0.34 \mathrm{~s}$ on line 5-7 at a distance of $30 \mathrm{~km}$ from bus- 5 for $0.04 \mathrm{sec}$ and at the same time another LLL fault is created at line 8-9 at $0.35 \mathrm{sec}$ for $0.04 \mathrm{sec}$. The wave forms obtained from this case is studied below :

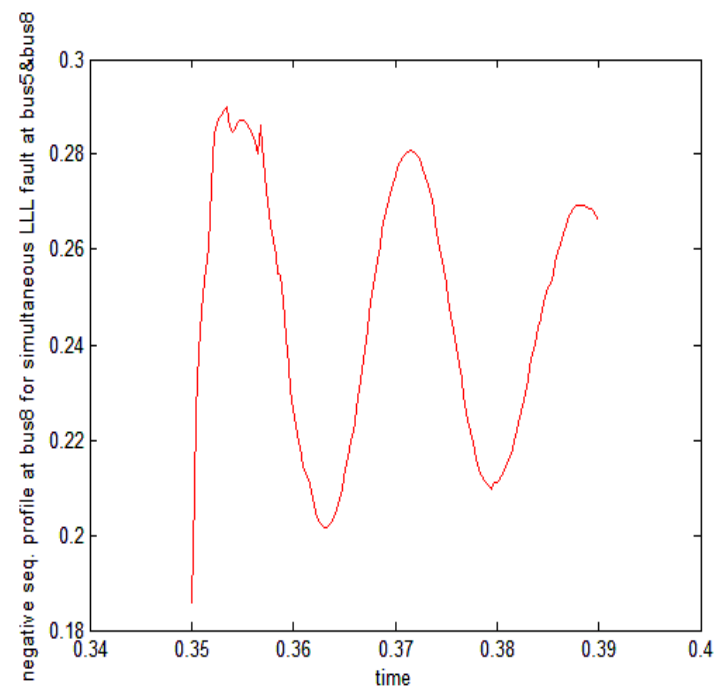

Fig.14(a). Negative Sequence Profile at bus8.

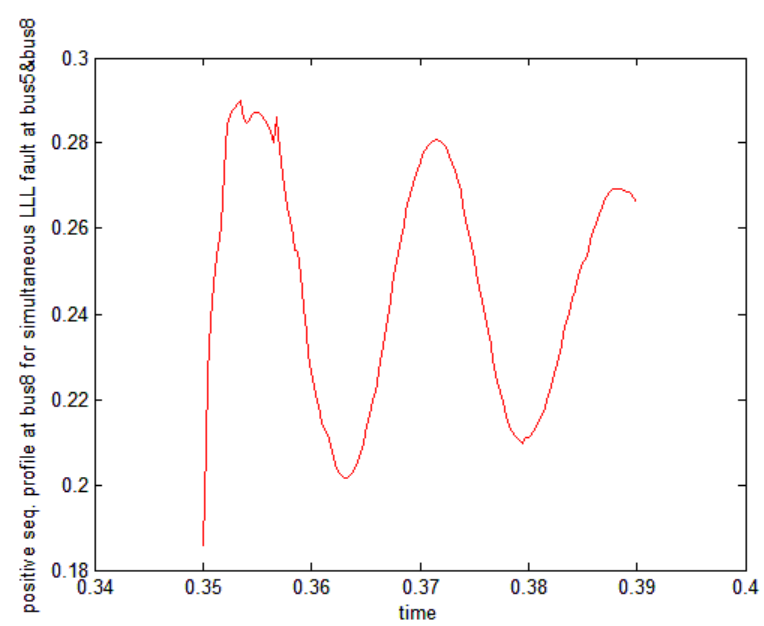

Fig.14(b). Positive Sequence Voltage Profile at bus8.

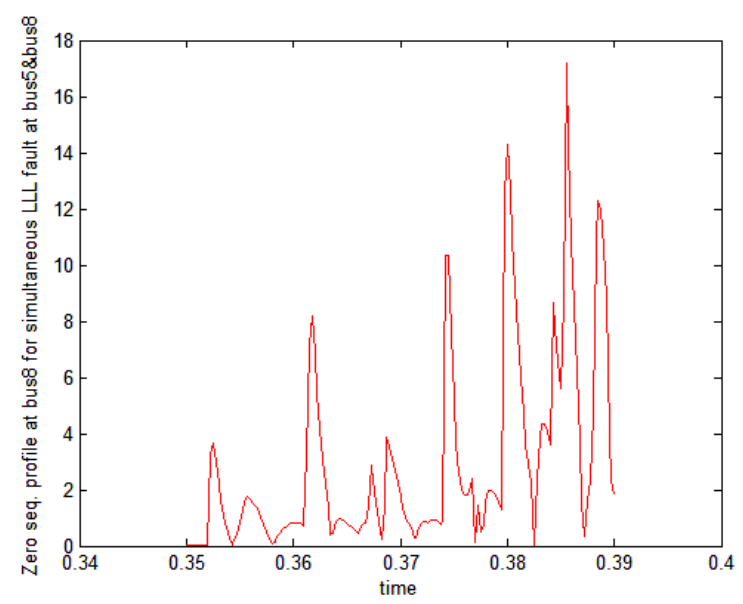

Fig.14(c). Zero Sequence Voltage Profile at bus8. 


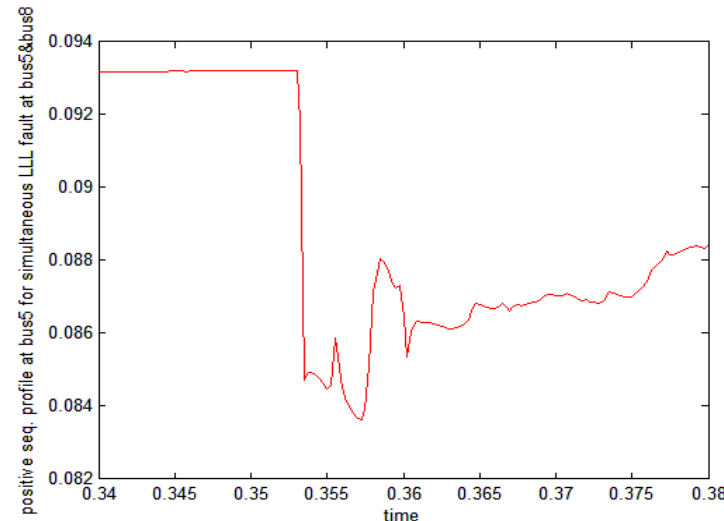

Fig.15(a ). Positive Sequence Voltage Profile at bus5.

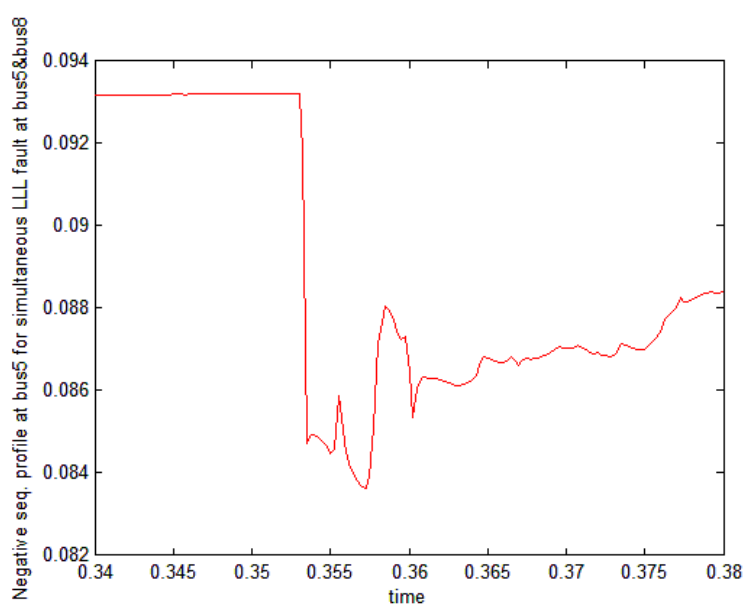

Fig.15(b). Negative Sequence Profile at bus5.

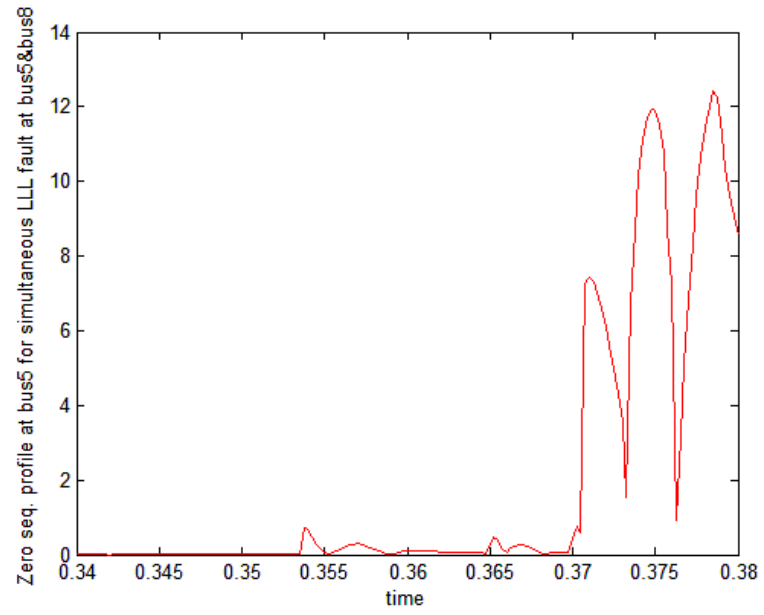

Fig.15(c). Zero Sequence Voltage Profile at bus5.

From the sequence voltage (positive, negative and zero) profiles at both the buses, it is evident both the buses individually satisfying the pickup criterion for a balanced fault.

b) Bus5 with LLL and Bus 9 with LLG Fault:

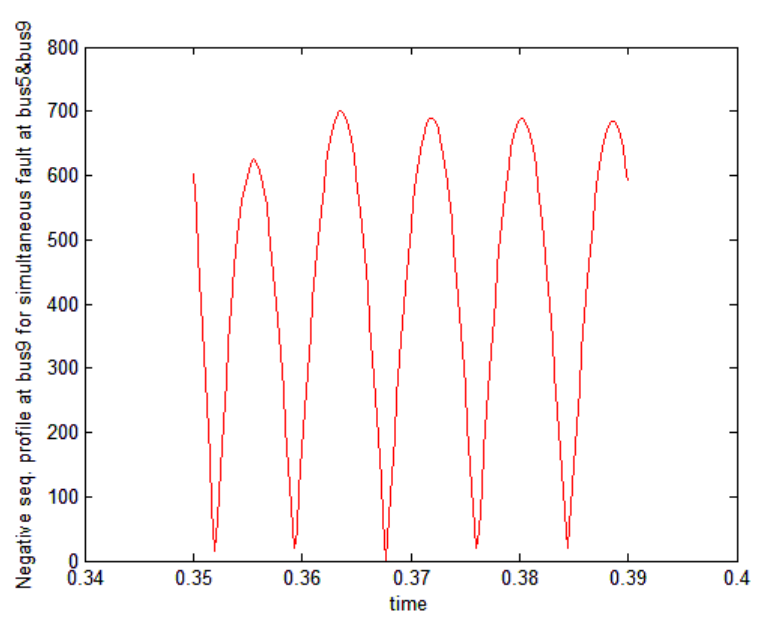

Fig.16(a). Negative Sequence Profile at bus9

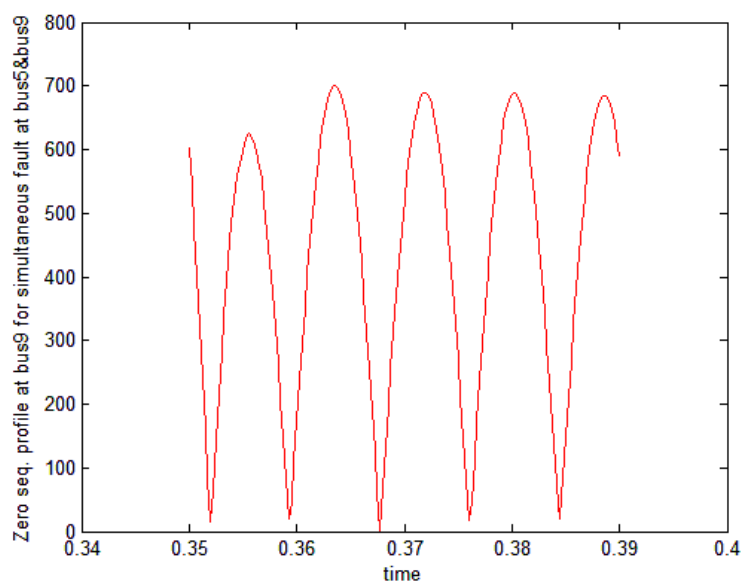

Fig.16(b). Zero Sequence Profile at bus9.

Here also both the sequence voltage profiles will satisfy their individual fault pick up criterion. However, depending on source, load and measurement errors in each substation and circumstances some samples may deviate from the pickup criteria. During critical conditions of power systems like- load encroachment and power swing conditions, the positive sequence impedance may enter zone 3 of relay which can cause undesired tripping of lines. But in those cases FLI criterion will not satisfy and thus such events will declare as a non-fault situation by the scheme. Thus WABP Scheme mitigates the problem raised during critical conditions of power network (e.g-load encroachment and power swing conditions). So, this scheme works fine for Zone 3 protection support also.

\section{Case-iv: Sources of error/Limitation: Simultaneous Faults at different Lengths of the same Line :}

A-G fault is created at Line 5-7 at $0.32 \mathrm{sec}$ for $0.04 \mathrm{sec}$ at $30 \mathrm{KM}$ distance from bus 5 and at the same time another fault is created on the same line and almost at the same distance (within $1 \mathrm{~km}$ ) for $0.34 \mathrm{sec}$ for $0.04 \mathrm{sec}$ which is a 3-phase fault. Now the fault voltage profile from $0.32 \mathrm{sec}$ to $0.38 \mathrm{sec}$. for bus 5 is indicated as follows: 


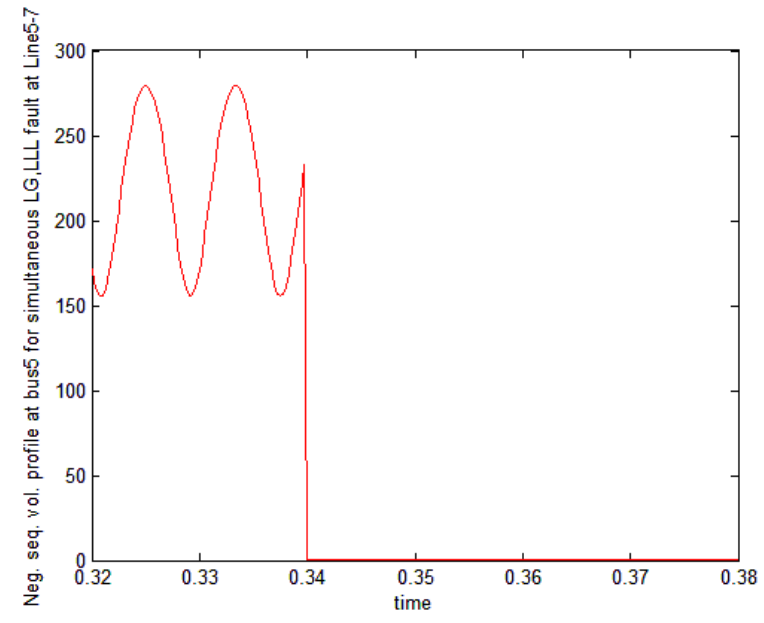

Fig.17(a). Negative Sequence Profile at bus5.

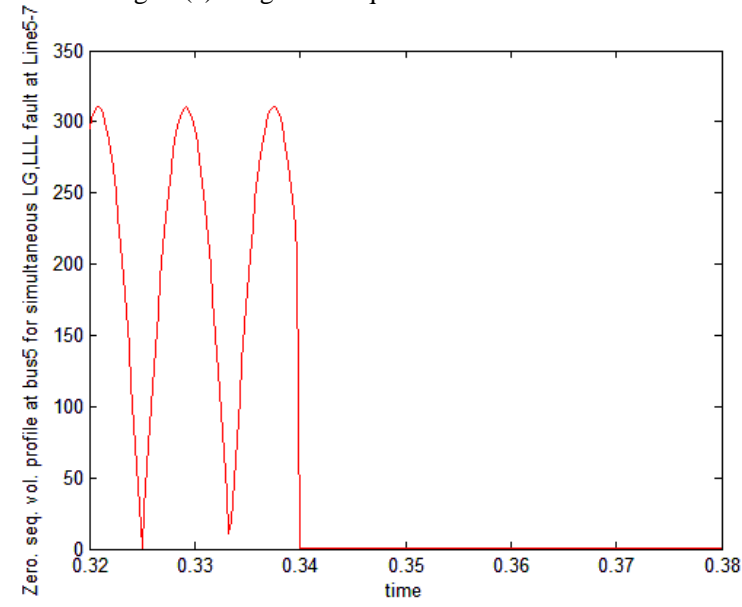

Fig.17(b). Zero Sequence Profile at bus5.

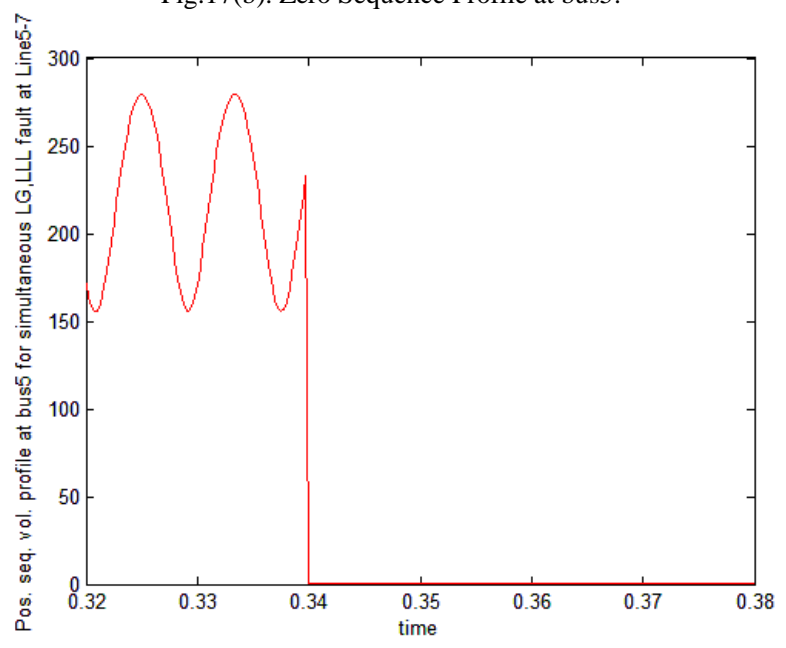

Fig.17(c). Positive Sequence Profile at bus5.

From the above figure no. 17(a), 17(b),17(c), it is clear that resultant waveforms having two parts.

i) up to $0.32-0.34$ sec., it is obeying the pickup criterion of an unbalanced fault and

ii) $\quad 0.34-0.38 \mathrm{sec}$, the waveforms are obeying the pickup criterion for a balanced fault.
Theoretically, the wave should have three parts, $0.32-0.34 \mathrm{sec}$. unbalanced fault, $0.34-0.36 \mathrm{sec}$ both balanced and unbalance fault exist in the line and 0.36-0.38 sec balanced fault exist in the line. Here the circuit is obeying superposition theorem of network. As 3-phase fault is the most severe fault in the circuit, it nullifies the effect of an unbalanced fault and predominates. So, with this scheme if some balanced fault is indicating, it may contain some percentage of simultaneous unbalanced faults also, in the line as faults in power system is not an isolated issue. This scheme is showing unbalanced fault means the line contains unbalanced faults only but in case of balanced fault, the line may contain some percentage of unbalanced faults also.

So, existence of Simultaneous faults in the same Line is confirmed with logic shown below.

i) Balanced + Unbalanced- Output Balanced

ii) Balanced+ Balanced- Output Balanced

iii) Unbalanced + Balanced- Output Balanced

iv) Unbalanced +Unbalanced -Output Unbalanced

With the existing scheme, it is difficult to distinguish the simultaneous faults in a same line. Moreover, depending on the several parameters and constraints of the power system like - source strength, demand of load and other errors in measurement and operation, some samples may deviate from their own pick up criterion sometimes.

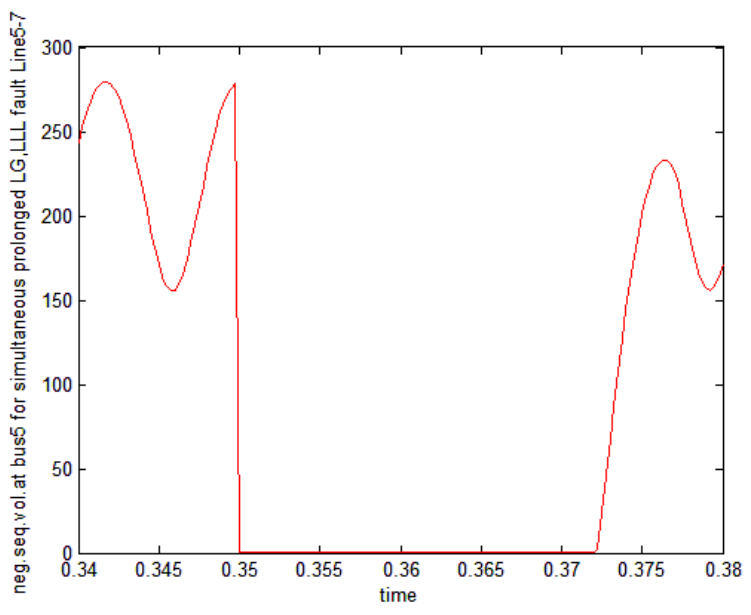

Fig.18. Negative Sequence Profile at bus5.

Fig.18 is another case study, where an A-G fault is created at $0.34 \mathrm{sec}$ for $0.04 \mathrm{sec}$ on Line 5-7 at 30KM distance, at the same time another close in fault which is a 3 -phase fault by nature is created on the same line for $0.02 \mathrm{sec}$. same as previous case between $0.35-0.37 \mathrm{sec}$., the balanced fault predominates and suppressed the effect of unbalanced A-G fault and once the balanced fault is cleared, between 0.37-0.38 $\mathrm{sec}$, the effect of unbalanced fault is again seen. Thus output is a composite figure in nature. So, in the presence of a balanced fault, the effect of unbalanced fault cannot be distinguished as LLL fault predominates with respect to its degree of severity than LG fault. LLL is the most severe fault, however most occurred fault in power system is LG fault. Around over 70\% fault occurred in the power systems are generally LG fault and 
a perfect symmetrical fault occurred in a power system is seen to be very rare.

\section{CONCLUSIONS}

A Novel WABP scheme based on synchronized phasor measurements is proposed in this paper which can improve the operation of power system in several respects. The sequence components of voltage, phase angles and the sign of cosine of the angle between voltage and current at both ends of a line is used to identify the faulted area and faulted branch. Simulation results for the nine-bus power system show that the method performs accurately during several faults in systems, interconnected systems and simultaneous faults. Other than the simple setting principles, the scheme has the ability to distinguish the fault from load encroachment and power swing and can mitigate the shortcomings of the conventional backup protection scheme. It is helpful to prevent blackouts. Thus with the context of today's backup protection schemes, the scheme described here is commendable.

\section{APPENDIX A}

System data for 3-machine 9-bus configuration:

\section{Gererators}

Gen-1: 600 MVA,22KV,50HZ

Gen-2: 465 MVA,22KV,50HZ

Gen-3: 310 MVA,22KV,50HZ.

\section{Transformers}

T1: $600 \mathrm{MVA}, 22 / 400 \mathrm{KV}, 50 \mathrm{HZ}, \mathrm{D} / \mathrm{Y}$;

T2: 465 MVA,22/400KV,50HZ,D/Y;

T3: 310 MVA,22/400KV,50HZ,D/Y;

\section{Transmission line:}

Length of line $7-8=320 \mathrm{Km}$, line $8-9=400 \mathrm{Km}$,line 7 $5=310 \mathrm{Km}$., line $5-4=350 \mathrm{Km}$,line $6-4=350 \mathrm{Km}$,line $6-9=300 \mathrm{~km}$.

\section{Loads}

Load $A=300 M W+j 100 M V A r$.

Load $B=200 M W+j 75 M V A r$.

Load $\mathrm{C}=150 \mathrm{MW}+\mathrm{j} 75 \mathrm{MVAr}$.

Other parameter used are same as used in Reference [11].

\section{REFERENCES}

[1] S. Horowitz and A. G. Phadke, "Third zone revisited", IEEE Transactions on Power Delivery, Vol.21, No.1, pp.23-29, Jan.2006.

[2] J.D. Ree, V. Centeno, J.S. Thorp, and A.G. Phadke, "Synchronized phasor measurement applications in Power systems, "IEEE Transactions on .Smart Grid, Vol.1, No.1, pp.20-27, June 2010.

[3] A.G. Phadke and J.S. Thorp, Synchronized Phasor Measurements and Their Applications. New York: Springer, 2008.

[4] M.M. Eissa, M. E. Masoud, and M.M.M. Elanwar, "A novel backup wide area protection technique for power transmission grids using phasor measurement unit, "IEEE Transactions on Power Delivery, Vol.25, No.1, pp. 270-278, Jan. 2010.

[5] P.V. Navalkar and S. A. Soman, "Secure remote backup protection of transmission lines using synchrophasors", IEEE Tranactions on Power Delivery, Vol.26, No.1, pp.87-96, Jan. 2011.

[6] H. Lin, S. Sambamoorthy, S. Shukla, J. Thorp, and L. Mili, "Ad-hoc vs. supervisory wide area backup relay protection validated on power/network co-simulation platform", presented at the $17^{\text {th }}$ Power System Computation Conference., Stockholm, Sweden, Aug. 22-26, 2011.
[7] J. Ma, J. Li, J. S. Thorp, A. J. Arana, Q. Yang, and A. G. Phadke, “A fault steady state component-based wide area backup protection algorithm", IEEE Transactions on Smart Grid, Vol.2, No.3, pp.468475, Sep.2011.

[8] Z.He, Z. Zhang,W. Chen,O. P.Malik, and X. Yin,"Wide-area backup protection algorithm based on fault component voltage distribution", IEEE Transactions on Power Delivery, Vol.26, No.4, pp.2752-2760, Oct. 2011.

[9] B. Kasztenny, "Distance protection of series-compensated lines:problems and solutions", presented at the $28^{\text {th }}$ Annual Western Protective Relay Conference, Spokane, WA, USA, Oct. 22-25, 2001.

[10] D. Novosel, A. G. Phadke, M.M. Saha, and S. Lindahl, "Problems and solutions for microprocessor protection of series compensated lines", in Proceedings of Conference Development of Power System Protection, 1997, pp.18-23.

[11] Paresh Kumar Nayak, Ashok Kumar Pradhan, and Prabodh Bajpai, "A Fault Detection Technique for the Series compensated Line During Power Swing", IEEE Transactions on Power Delivery, Vol.28, No.2, April 2013, pp.714-722.

[12] S.N.Muneswar, R.Hasabe, D.Shelar, P.Kose, "A New Adaptive PMU based Protection Scheme for Interconnected Transmission Network System," 2014 International Conference on Circuit, Power and Computing Technologies [ICCPCT].

[13] P.K. Nayak, A.K. Pradhan, and P. Bajpai, "Wide-Area MeasurementBased Backup Protection for Power Network with Series Compensation", IEEE Transactions on Power Delivery, V.29, No.4, August 2014, pp.1970-1977.

[14] A.K. Pradhan, P. Jena, "Directional relaying in the presence of a thyristor-controlled series capacitor", PES General Meeting Conference \& Exposition, 2014 IEEE, 27-31 July 2014.

[15] T. Routtenberg, Yao Xie, R.M. Willett, Lang Tong, "PMU Based Detection of Imbalance in Three-Phase Power Systems", IEEE Transactions on Power Systems ,Vol.30, No.4, July2015, pp.19661976.

[16] Ali.H.Al Mohammed, M.A. Abido, "A Fully Adaptive PMU-Based Fault Location Algorithm for Series compensated Lines", IEEE Transactions on Power Systems, Vol.29, No.5, September 2014, pp.2129-2137.

[17] I. Kamwa, S.R. Samantaray, G. Joos,"Wide Frequency Range Adaptive Phasor and Frequency PMU Algorithms", IEEE Transactions on Smart Grid,Vol.5, No.2, March 2014, pp.569-579.

[18] P. Kundu, A.K. Pradhan, "Online identification of Protection element failure using wide area measurements", IET Generation, Transmission and Distribution, 2015,Vol.9, No.2, pp.115-123.

[19] S. Roy, P.S. Babu, "Power swing protection of series compensated transmission line with novel fault detection technique“, IEEE International Conference on Green Computing, Communication and Electrical Engineering [ICGCCEE], 6-8 March 2014, Coimbatore.

\section{BIOGRAPHIES}

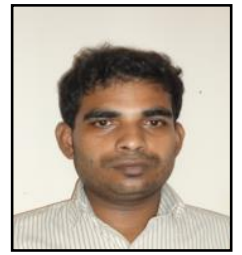

SAPTARSHI ROY, received the B.E degree in Electrical Engineering from Jadavpur University, West Bengal, India in 2009.Received M.Tech degree from NIT WARANGAL in 2014. Currently he is pursuing $\mathrm{PhD}$ in Electrical Engineering in the department of Electrical Engineering, National Institute of Technology, Warangal, India. His areas of interest are power system protection, Phasor Measurement Unit applications in power systems, Synchro-phasors applications in power systems.

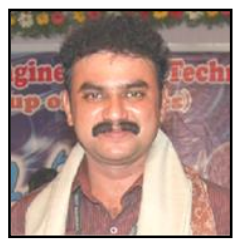

SURESH BABU PERLI, Currently he is working as an Assistant Professor in Department of Electrical Engineering, National Institute of Technology, Warangal. His areas of interest are Power System Protection with digital multifunction relays, Development of Adaptive protection schemes and Digital filtering algorithms. 